\title{
Assessing public speaking fear with the short form of the Personal Report of Confidence as a Speaker scale: confirmatory factor analyses among a French-speaking community sample
}

\author{
This article was published in the following Dove Press journal: \\ Neuropsychiatric Disease and Treatment \\ 2 May 2013 \\ Number of times this article has been viewed
}

\section{Alexandre Heeren ${ }^{1,2}$ \\ Grazia Ceschi ${ }^{3}$ \\ David P Valentiner ${ }^{4}$ \\ Vincent Dethier' \\ Pierre Philippot ${ }^{\prime}$}

'Université Catholique de Louvain, Louvain-la-Neuve, Belgium; ${ }^{2}$ National

Fund for Scientific Research, Brussels, Belgium; ${ }^{3}$ Department of Psychology, University of Geneva, Geneva, Switzerland; ${ }^{4}$ Department of Psychology, Northern Illinois University, DeKalb, IL, USA
Correspondence: Alexandre Heeren Laboratory of Experimental Psychopathology, Institute of Psychological Science, Université Catholique de Louvain, Place du Cardinal Mercier, I0, B-1348 Louvain-la-Neuve, Belgium

$\mathrm{Tel}+32497882315$

Fax +3210473774

Email alexandre.heeren@uclouvain.be
Background: The main aim of this study was to assess the reliability and structural validity of the French version of the 12-item version of the Personal Report of Confidence as Speaker (PRCS), one of the most promising measurements of public speaking fear.

Methods: A total of 611 French-speaking volunteers were administered the French versions of the short PRCS, the Liebowitz Social Anxiety Scale, the Fear of Negative Evaluation scale, as well as the Trait version of the Spielberger State-Trait Anxiety Inventory and the Beck Depression Inventory-II, which assess the level of anxious and depressive symptoms, respectively.

Results: Regarding its structural validity, confirmatory factor analyses indicated a single-factor solution, as implied by the original version. Good scale reliability (Cronbach's alpha $=0.86$ ) was observed. The item discrimination analysis suggested that all the items contribute to the overall scale score reliability. The French version of the short PRCS showed significant correlations with the Liebowitz Social Anxiety Scale $(r=0.522)$, the Fear of Negative Evaluation scale $(r=0.414)$, the Spielberger State-Trait Anxiety Inventory $(r=0.516)$, and the Beck Depression Inventory-II $(\mathrm{r}=0.361)$.

Conclusion: The French version of the short PRCS is a reliable and valid measure for the evaluation of the fear of public speaking among a French-speaking sample. These findings have critical consequences for the measurement of psychological and pharmacological treatment effectiveness in public speaking fear among a French-speaking sample.

Keywords: social phobia, public speaking, confirmatory factor analysis

\section{Introduction}

About $77 \%$ of the general population fears public speaking. ${ }^{1}$ Public speaking fear is highly prevalent and manifests itself as a significant burden in society through lower educational achievement, occupational impairment, and increased health care utilization. $^{2-4}$ At a diagnostic level, fear of public speaking is usually diagnosed as social anxiety disorder (SAD), nongeneralized type. ${ }^{5,6}$ Recent studies confirm that fear of public speaking is a frequent feature of SAD, but that it may also be present in the absence of any or most of the other features of SAD. ${ }^{7,8}$ On the whole, there seems to be substantial, although not conclusive, evidence that the disorder may be a specific subtype and not just a minor form of SAD. ${ }^{9}$

At a clinical level, recent studies confirm that public speaking anxiety is amenable to cognitive-behavioral therapy programs that include exposure to the feared situations, ${ }^{10}$ including novel methods of exposure, such as virtual reality environments 
and exposure to videotaped audiences. ${ }^{11-13}$ Several studies report that computerized cognitive bias modification training may significantly alleviate discomfort in individuals' speech performance. ${ }^{14-16}$ Recent findings also pointed out that there are additional treatment modalities, such as the administration of cannabidiol or D-cycloserine prior to exposure, which might enhance the efficacy of currently available cognitivebehavioral therapy programs. ${ }^{17,18}$

As a consequence of this high prevalence of public speaking fear, and in light of its clinical implications, the need for brief and accurate measurement of this construct is critical. There are few measures with the specific aim of measuring public speaking fears, such as Report of Communication Apprehension, ${ }^{19}$ Self-statements During Public Speaking, ${ }^{20}$ and the Personal Report of Confidence as Speaker (PRCS). ${ }^{21,22}$

Of these measures, one of the most frequently used and well established is the PRCS..$^{21,22}$ The original PRCS was a self-report scale consisting of 104 true or false items designed to measure a subject's fear of public speaking. ${ }^{21}$ Subjects were asked to base their responses on their most recent experience of speaking in front of an audience; however, this version proved to be cumbersome when used as a screening instrument. Therefore, a short 30-item format version was developed by selecting the 30 most discriminating items from the longer questionnaire. ${ }^{22}$ Similar to the long version, the questionnaire is arranged in a true or false format, with a total score ranging from 0 (no fear, all items scored as "false") to 30 (extreme fear, all items scored as "true").

Since its development, the 30-item format version of the PRCS has been widely used as a screening measure in national and international epidemiologic surveys dealing with fear of public speaking. ${ }^{22-24}$ It has also been frequently used as an outcome measure of psychological and pharmacological treatment effectiveness in public speaking fear. ${ }^{25-29}$ Its score did not significantly differ across gender or ethnicity in a college-aged sample,$^{30}$ and normative data for the PRCS have been published. ${ }^{30}$

Until recently, psychometric properties of the PRCS have received little empirical attention. A previous study reported that it had a high internal consistency (Cronbach's alpha $=0.91)$ and exhibited adequate convergent validity (ie, having significant correlations with 12 other measures of speech and social anxiety, ranging from 0.52 to 0.97$){ }^{31}$ Higher PRCS scores were shown to be associated with less effective speech performance. ${ }^{32}$

To our knowledge, only one study assessed the structural validity of the scale. ${ }^{33}$ At a more fundamental level, structural validity is a critical point. This refers to the degree to which the scale measures the theorized construct that it purports to measure. In other words, structural validity involves generalizing from one measure to the concept of this measure. Hook et $\mathrm{al}^{33}$ submitted the original 30 PRCS-items to an exploratory factor analyses. The results indicated that the data were best explained by a two-factor solution, accounting for $95 \%$ of the variance. Between the two factors, the first was comprised mostly of word items presented in a straight forward manner (ie, 12 straightforwardly worded items and two reversed worded items) and the second consisted of reversed scored items only. As a consequence, the authors decided to eliminate the two reversed scored items from the first factor to yield a straightforwardly worded, 12-item scale. Exploratory factor analyses of this 12-item scale indicated that it accounted for the initial $84 \%$ of the PRCS variance, with items for the second factor accounting for the remaining $11 \%$ of the PRCS variance. Factor 1 and factor 2 were significantly correlated with each other $(r=0.59)$. Moreover, both factors were significantly correlated with the 30 -item version. As pointed out by the authors, this suggested that the straightforwardly worded 12-item scale adequately reflects the theorized psychological construct that it purports to measure.

Moreover, the 12 straightforwardly worded items widely surpassed the other versions of the PRCS, in regards to evidence of convergent and divergent validity. For instance, it significantly exhibited a positive correlation with similar construct such as social phobia scale $(r=0.54)$, Spielberger State-Trait Anxiety Inventory (STAI-Trait) $(r=0.44)$, and moderately correlated with a less convergent construct such as the Beck Depression Inventory-II (BDI-II) $(r=0.34)$. Furthermore, it had high reliability (Cronbach's alpha $=0.85$ ), and the total score exhibited a good distribution as depicted by a mean of $4.6(\mathrm{SD}=3.51)$, a skewness of 0.33 , and a kurtosis of -1.1 .

As a consequence of these results, the use of the 12-item version has been recommended..$^{33}$ Moreover, due to its brief format, this version has been depicted as a promising tool for screening research; ${ }^{33}$ however, no previous study using confirmatory factor analysis has tested whether this 12 straightforwardly worded items scale effectively fits with a single-factor solution. As previously pointed out, structural validity is critical, so using confirmatory factor analysis in order to test that the 12 -item version best fits with a singlefactor solution would ensure that one can generalize from this measure to the concept. In addition to this first limitation, no cross-cultural adaptation of the 12-item version has been conducted, although the 30-item format version was adapted and validated among a Spanish-speaking sample. ${ }^{34,35}$ 
This is an important issue as it ensures the generalization of the measured construct. Thus, the systematic validation of a French version represents an important contribution in its own right, especially given the fact that French is the official language in 32 countries and territories worldwide. The present study was designed to overcome these two central limitations by answering two main questions. First, does the 12-item scale version fit with a single-factor solution? Second, while no French adaptation and validation of the PRCS has yet been published, could the good features of the 12 -item version depicted by Hook et $\mathrm{al}^{33}$ be replicated in a French-speaking sample? Consequently, the present study was designed to translate and validate the 12-item format PRCS into French.

\section{Material and methods Overview}

The scale was first translated into French. Next, the structural validity of the French version of the scale was tested with confirmatory factor analyses (due to a prior prediction of a single-factor solution, as found by Hook et $\mathrm{al}^{33}$ ). Subsequently, we examined reliability estimates as well as convergent and divergent validity of the scale.

\section{French adaptation of the scale}

We followed the steps for the transcultural validation of psychometric instruments detailed by Hambleton et al. ${ }^{36}$ Items were first translated into French and then back-translated into English. Two fully bilingual experts translated the original English scale into French using a committee approach. The French version was then translated back into English and reevaluated by two other bilingual experts. The first author supervised the whole translation/back-translation process. Experts were instructed to verify the conformity of the retranslated English version with the original version and the precision of the French items. Items with problematic back-translation were thoroughly discussed and appropriately amended. Most discrepancies were minor, involving the choice between two synonyms. Regarding the use of an appropriated format for the items, five participants were then instructed to comment on the overall presentation of the instrument and the precision of the items. No remarks were made. The French version of the scale is provided in Table S1.

\section{Structural validation}

\section{Participants}

Six hundred and eleven French speaking volunteers (410 women, 67.1\%) were administered the French version of the PRCS. Their age ranged from 18 to 74 years $(\mathrm{M}=31.16, \mathrm{SD}=12.18)$. They were recruited from the Université Catholique de Louvain community (Belgium) and the University of Geneva (Switzerland). The first, second, and last authors sent emails to potential participants (acquaintances and French-speaking international colleagues) requesting participation in a study on a voluntary basis and circulated this invitational email to others (snowball principle-emailing). Regarding their nationality, $57.4 \%(\mathrm{n}=351)$ of the participants were from Switzerland, $17.5 \%(n=107)$ from France, $13.3 \%(n=81)$ from Belgium, $11.1 \%(n=68)$ from French-speaking African countries, and $0.7 \%(n=4)$ from Canada (Quebec). Participants were predominantly university graduates $(83.5 \%[\mathrm{n}=510])$, while $7.5 \%(n=46)$ of the participants had a college degree, $6.7 \%(n=41)$ had a high school degree, $2 \%(n=12)$ had a middle school degree, and $0.3 \%(n=2)$ had an elementary school degree. Only native French speakers completed the questionnaire.

\section{Measures and procedures}

We asked participants to complete the French versions of the PRCS, the Liebowitz Social Anxiety Scale (LSAS), ${ }^{37}$ the Fear of Negative Evaluation scale (FNE), ${ }^{38}$ as well as the STAI-Trait, ${ }^{39}$ and the BDI-II, ${ }^{40}$ which assess the level of anxious and depressive symptoms, respectively. We selected these last scales to ensure that the PRCS best differentiates fear of public speaking from general anxiety proneness and depressive symptoms. Previous studies have reported that the STAI-Trait and the BDI-II are both relevant measures for the assessment of the construct validity for a scale referring to a sample of emotional behaviors. ${ }^{41,42}$

The STAI-Trait is a 20-item, self-report questionnaire assessing anxiety proneness. The French adaptation of the scale has reported good metric properties. ${ }^{43}$ Cronbach's alpha in the current sample was 0.87 .

The BDI-II is a 21-item, self-report measure of symptoms of depression. The French adaptation of the scale has reported good metric properties. ${ }^{40}$ Cronbach's alpha in the current sample was 0.86 .

The LSAS is a 24-item scale that measures anxiety and avoidance of social interaction and performance situations. The French adaptation of the scale has reported good metric properties. ${ }^{44}$ Cronbach's alpha in the current sample was 0.91 .

The FNE is a 30 -item self-report questionnaire that measures a person's apprehension about negative evaluation. 
Studies have reported good psychometric properties as well as structural validity of the French adaptation of the scale. ${ }^{45}$ Cronbach's alpha in the current sample was 0.91 .

\section{Data analysis}

Confirmatory factor analysis, using AMOS 16 software (IBM Statistics, Chicago, USA) was used to test the factorial validity of the PRCS. ${ }^{46}$ Before performing the analysis, we conducted the Kolmogorov-Smirnov test on each item of the PRCS. These analyses revealed that normality was achieved for all items $(P>0.05)$.

Concerning the confirmatory factor analyses, goodness of fit was tested with a $\chi^{2}$ test (a statistically nonsignificant value corresponds to an acceptable fit); however, this method is sensitive to sample size. Indeed, it has been noted that obtaining statistically nonsignificant $\chi^{2}$ when performing confirmatory factor analyses is unusual, even if the discrepancy of the observed from the implied data is trivial. ${ }^{47}$ We preferred a derived fit statistic, the normed $\chi^{2}$, which is less dependent on the sample size. The normed $\chi^{2}$ is achieved by computing the ratio of the model $\chi^{2}$ and the degrees of freedom. ${ }^{48}$ A normed $\chi^{2}$ below 2 usually suggests a good model fit, and a normed $\chi^{2}$ below 3 suggests an acceptable fit. ${ }^{49}$

Many other solutions to the problem of sample size dependence have been proposed, and consequently, many different fit indices are available. Following recent recommendations in the report of fit indices, ${ }^{50}$ we reported the standardized root mean square residual (SRMR), the root mean square error of approximation (RMSEA), and the comparative fit index (CFI). SRMR and RMSEA are both residuals-based, absolute fit measures. The CFI is an incremental relative fit measure. The combination of RMSEA and SRMR is valuable because the SRMR is sensitive to the misspecification of the factor covariances, whereas the RMSEA is sensitive to the misspecification of factor loadings. ${ }^{51}$ In this way, if both indices were accepted, then the latent and the measurement model would be considered to be well specified. Moreover, the RMSEA has the advantage of usually being associated with a confidence interval. RMSEA values less than 0.06 were found to indicate a good model of fit. ${ }^{52,53}$ The SRMR are expected to stay below $0.08 .52,53$

The CFI indicates a good model fit for values in the range between 0.95 and 1.0, whereas values in the range of 0.90 and 0.95 signify an acceptable fit. ${ }^{54,55}$ The goodness of fit Index (GFI) was also reported. GFI is an absolute fit index, ${ }^{34}$ which is analogous to R-square and performs better than any other absolute fit index regarding the absolute fit of the data. ${ }^{56,57}$ GFI values are between 0 and 1 , with 1 indicating a perfect fit. A value of 0.90 has usually been considered as a minimum for model acceptance. ${ }^{54}$

\section{Results}

\section{Structural validity}

To be consistent with previous studies, we first imposed on the data the model proposed by Hook et $\mathrm{al}^{33}$ (model A). As shown in Table 1, analyses indicated that model A exhibited a low overall fit.

The maximum modification indices in the $\theta-\Delta$ matrix (covariance between errors on observed variables) were found between items 1 and 8, 3 and 12, 4 and 11, 5 and 11, as well as between items 4 and 5 . Hence, we let these pairs of errors covariate because they were semantically very similar. Items 1 and 8 both refer to "physiological responses" (item 1: "My hands tremble when I try to handle objects on the platform;" item 8: "I perspire and tremble just before getting up to speak"). Items 3 and 12 both refer to "speech apprehension" (item 3: "While preparing a speech I am in a constant state of anxiety;" item 12: "I am terrified at the thought of speaking before a group of people"). Items 4 and 11 both refer to "thought confusion" (item 4: "My thoughts become confused and jumbled when I speak before the audience;" item 11: "It is difficult for me to search my mind calmly for the right words to express my thoughts"). Both pairs of items 5 and 11 and items 4 and 5 refer to "searching for her/his words" (item 5: "Although I talk fluently with friends, I am at a loss for words on the platform;" item 11: "It is difficult for me to search my mind calmly for the right words to express my thoughts;" item 4: "Thoughts become confused and jumbled when I speak before the audience").

As a consequence, we compared the fit of model $\mathrm{A}$ with a model B similar to model A, but letting these pairs

Table I Fit index values for the different tested models

\begin{tabular}{lllllllll}
\hline Model & $\chi^{2}$ & df & Normed- $\chi^{2}$ & SRMR & RMSEA & RMSEA 90\% CI & GFI & CFI \\
\hline Model A & 245.156 & 54 & 4.54 & 0.011 & 0.076 & $0.067-0.086$ & 0.902 & 0.914 \\
Model B & 140.625 & 49 & 2.87 & 0.008 & 0.055 & $0.045-0.066$ & 0.964 & 0.959 \\
Model C & 30.946 & 10 & 3.09 & 0.006 & 0.059 & $0.036-0.083$ & 0.986 & 0.986 \\
\hline
\end{tabular}

Note: Model B is the best fitting model.

Abbreviations: df, degrees of freedom; SRMR, standardized root mean square residual; RMSEA, root mean square error of approximation; Cl, confidence interval; GFI, goodness of fit index; CFI, comparative fit index. 
of errors covariate. As shown in Table 1, a reasonable overall fit of the model was observed. Further, model B fit significantly better than model A, $\Delta \chi^{2}=104.531, \Delta d f=05$, $P<0.001$ (see Table 1 and Figure 1). However, it should be noted that the RMSEA is good but less than ideal in all the models we tested. As it has been pointed out, the RMSEA is very sensitive to small misspecifications of factor loadings, which are very common in the domain of personality and psychopathology research. ${ }^{58}$

Nevertheless, despite finding that the standardized factor loadings of Model B were all statistically significant ( $P<0.001$, see Table S2), five items showed loading below 0.40 (items $1,6,7,8$, and 9 ). As a consequence, we compared the fit of model B with a model similar to model B, but had excluded these items (model C). As shown in Table 1, the analyses indicated that despite the reasonable overall fit of model $\mathrm{C}$, model B fit significantly better than model $\mathrm{C}$ $\left(\Delta \chi^{2}=109.679, \Delta d f=39, P<0.005\right)$. As a consequence, in order to be consistent with the initial scale, we did not exclude these items. Furthermore, the items' descriptive statistics, as well as the scale score reliability for the summated scale if the item is deleted (see Tables 2 and 3), indicated that these items widely contribute to the good scale score reliability. In conclusion, these confirmatory factor analyses clearly suggested that model B fit the best.

\section{Descriptive statistics and internal consistency reliability}

Table 2 shows the descriptive statistics and scale score reliability indices of the French version of the PRCS. With an alpha higher than $0.75,{ }^{59}$ good scale score reliability was observed.

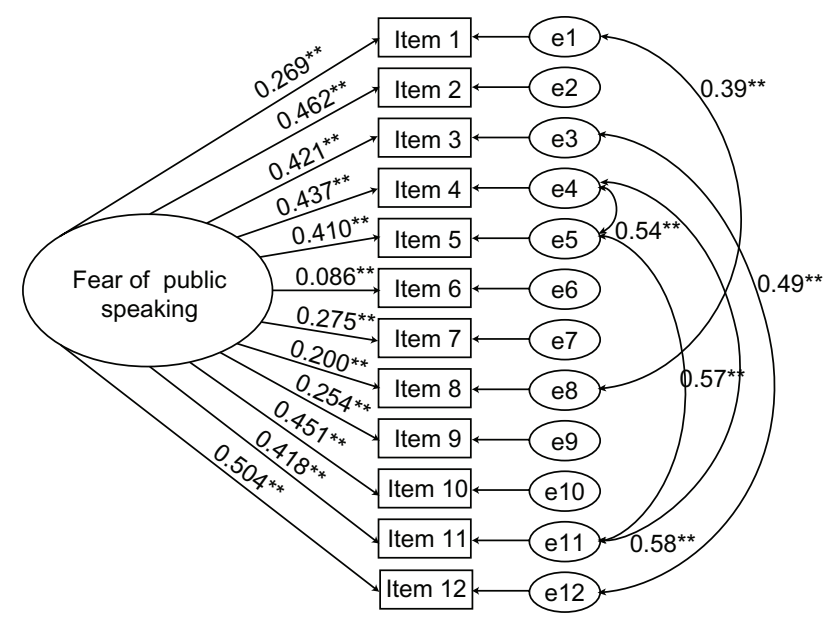

Figure I Path diagram depicting the single-factor solution (model B) of the French version of the short Personal Report of Confidence as a Speaker scale. Note: $* * P<0.01$.
Table 3 displays the descriptive statistics of each item and the consequences of deleting an item from the scale. For each item, the table shows the mean, variance, and the summated scale if the item was deleted. The results indicated that each item equally contributed to the summated scale. The last column exhibits the size of unstandardized alpha if the item is removed. Results suggested that all items contribute to the overall scale score reliability.

\section{Item analysis and discrimination analysis}

Table 4 displays the centile of the overall score. The results suggested that the overall score distribution is relatively symmetrical and bell-shaped, suggesting that the overall scale score correctly discriminates individuals.

Accordingly, we also conducted discrimination analysis using point biserial correlation coefficient $\left(\mathrm{r}_{\mathrm{pb}}\right)$ between each item and the overall scale score. As depicted in Figures 2 and 3, all the correlations were significantly positive, suggesting that the selection of a true value in each item significantly relates to higher overall score. However, even if significant, it should be noted that the item-total correlation was smaller for item 6 (often a minimum of 0.40 is used as a rule of thumb). The mean and variance of this item for the summated scale if it is deleted, as well as the size of unstandardized alpha if it is removed, suggested that this item is necessary for the overall good scale score reliability. As a consequence, we did not exclude these items.

\section{Correlations between the PRCS and other constructs}

Table 5 displays the zero-order correlations between the PRCS and the LSAS, the FNE, the BDI-II, as well as the STAI-Trait. Fisher's r-to- $z$ transformation and the Meng test of two correlations with one variable in common from the same sample were used to assess the difference of Pearson r-values. ${ }^{60}$ Both tests indicated that the PRCS correlates significantly better with the FNE, LSAS, and STAI-Trait than with BDI.

\section{Discussion}

The aim of this study was to propose an adaption of the 12-item version of the PRCS and to test, using confirmatory factor analyses, the validity of the single-factor solution these authors proposed. ${ }^{33}$ Confirmatory factor analyses showed that a single-factor solution has an acceptable fit.

The results indicated that the scale had very good internal reliability. Overall, our findings are in accordance with the exploratory factor analyses of Hook et al, ${ }^{33}$ endorsing 
Table 2 Descriptive statistics and Cronbach's alpha

\begin{tabular}{llllllll}
\hline & Items & Minimum & Maximum & M & SD & A & $\alpha$ 95\% Cl \\
\hline PRCS & 12 & 0 & 12 & 29 & 7.298 & 3.576 & 0.86 \\
FNE & 30 & 0 & 118 & 12.164 & 7.568 & 0.91 & $0.90-0.88$ \\
LSAS & 48 & 0 & 37 & 35.810 & 24.218 & 0.91 & $0.89-0.93$ \\
BDI-II & 21 & 0 & 68 & 8.63 & 6.836 & 0.86 & $0.83-0.87$ \\
STAI-Trait & 20 & 26 & 45.029 & 7.980 & 0.87 & $0.85-0.88$ \\
\hline
\end{tabular}

Abbreviations: PRCS, Personal Report of Confidence as a Speaker; FNE, Fear of Negative Evaluation scale; LSAS, Liebowitz Social Anxiety Scale; BDI-II, Beck Depression Inventory (2nd edition); STAI-Trait, Trait-version of the Spielberger State-Trait Anxiety Inventory.

the additive value of the short version of the PRCS. While the PRCS appears as one the most frequently used scales in assessing fear of public speaking, this is the first study using confirmatory factor analyses to test the structural validity of the 12-item version. This finding provides evidence that researchers and practitioners can generalize from this measure to the concept it purports to measure, even if the language in which the instrument is administered is different. Moreover, our findings suggest there is good reason to interpret scores of the 12-item version according to a single-factor solution, then referring to a global construct of fear of public speaking (ie, a unique overall scale score). At an applied level, these findings are important as they warrant that the score of an individual to the French version of the short PRCS may be compare to the other individuals PRCS score, even if the language in which the instrument is administered is different. These findings have critical consequences for the measurement of psychological and pharmacological treatment effectiveness in public speaking fear among a Frenchspeaking sample. They also bear important consequences for the use of the PRCS in the clinical setting.

We also examined the convergent validity of the scale. In accordance with Hook et $\mathrm{al}^{33}$ reporting stronger correlations

Table 3 Item-total descriptive statistics

\begin{tabular}{llllll}
\hline & M & SD & $\begin{array}{l}\text { Scale mean } \\
\text { if item } \\
\text { deleted }\end{array}$ & $\begin{array}{l}\text { Scale variance } \\
\text { if item deleted }\end{array}$ & $\begin{array}{l}\text { Alpha } \\
\text { if item } \\
\text { deleted }\end{array}$ \\
\hline Item I & 0.50 & 0.50 & 6.80 & 10.91 & 0.854 \\
Item 2 & 0.52 & 0.50 & 6.78 & 10.521 & 0.845 \\
Item 3 & 0.60 & 0.49 & 6.70 & 10.801 & 0.851 \\
Item 4 & 0.61 & 0.49 & 6.68 & 10.544 & 0.844 \\
Item 5 & 0.51 & 0.50 & 6.78 & 10.520 & 0.845 \\
Item 6 & 0.77 & 0.42 & 6.53 & 11.794 & 0.866 \\
Item 7 & 0.85 & 0.35 & 6.44 & 11.526 & 0.855 \\
Item 8 & 0.42 & 0.49 & 6.88 & 11.111 & 0.858 \\
Item 9 & 0.73 & 0.44 & 6.57 & 11.200 & 0.855 \\
Item 10 & 0.59 & 0.49 & 6.71 & 10.634 & 0.847 \\
Item II & 0.53 & 0.50 & 6.77 & 10.475 & 0.844 \\
Item 12 & 0.66 & 0.47 & 6.64 & 10.547 & 0.843 \\
\hline
\end{tabular}

Abbreviations: M, mean; SD, standard deviation; Alpha, Cronbach's alpha. between the 12-item version of the PRCS and measures of social anxiety as well as with trait anxiety than with depression, we found that the 12 -item version significantly correlates more to social anxiety and trait anxiety measurements than the depression measurement. This fits with earlier work showing that the PRCS has a good convergent validity. ${ }^{32}$

The present study suffers from several limitations. First, our sample was only comprised of nonclinical participants. Future studies should assess the structural validity of the PRCS among a clinical sample of individuals fearing public speaking. Second, we assessed the construct validity with self-report measures only. Future studies should examine the correlation between the PRCS and behavioral, as well as psychophysiological (eg, skin conductance, cortisol release) responses to speech situations (with multimodal assessment of public speaking fear). ${ }^{61,62}$ Third, our respondents were selected from the community via suboptimal snowball sampling methods, this limited the potential for generalization of the present findings. Data of factorial invariance across sex, age, nationality, and educational level would allow the examination of equivalence between scores on each subsample in order to improve the degree of generalization. However, neither the nationality nor the educational level (ie, 83.5\% are college graduates) of the present sample follow a distribution that allowed the use of such a statistical procedure. Future studies should further explore this issue. A fourth limitation is the Internet-administered format of the scales, since several studies show that the psychometric properties of scales and psychological tests administered via the Internet can be different from paper and pencil versions. ${ }^{63}$ Future studies should investigate this question regarding the PRCS. Finally, even if

Table 4 Centiles of the overall scale score distribution

\begin{tabular}{llllllll}
\hline Centiles & 5th & 10th & 25th & 50th & 75th & 90th & 95th \\
\hline Overall score & I & 2 & 4 & 8 & 11 & 12 & 12 \\
\hline
\end{tabular}

Notes: A centile (or percentile) is the value of a variable below which a certain percent of observations fall. For example, the 25th centile is the value (or score) below which 25 percent of the observations may be found. The 25 th centile is also known as the first quartile, the 50th centile as the median or second quartile, and the 75 th centile as the third quartile. 


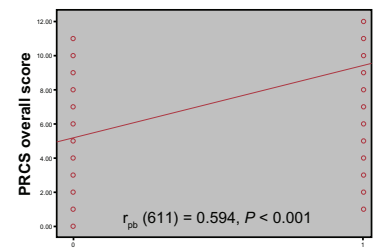

Item 1

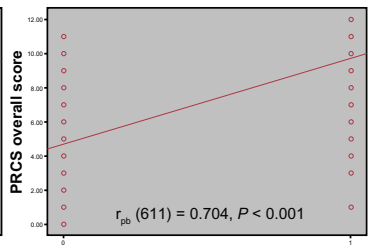

Item 2

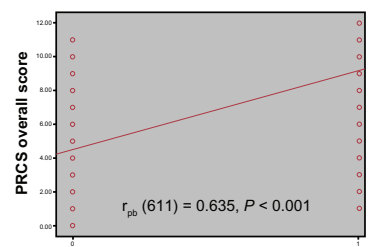

Item 3
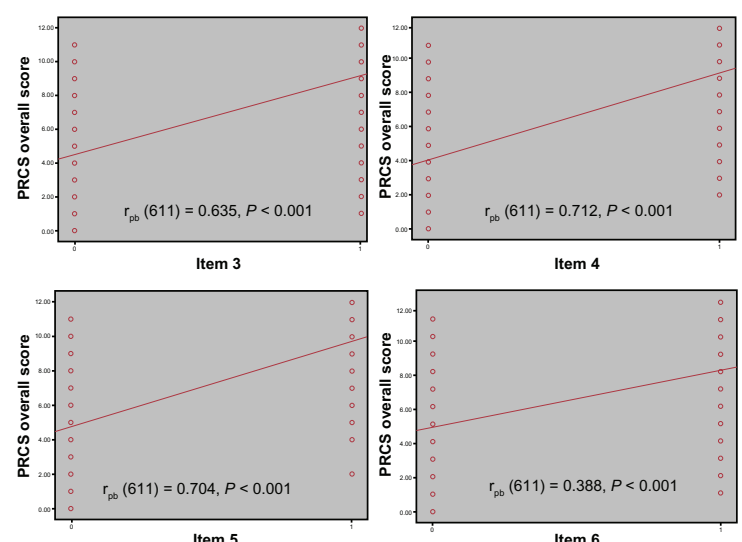

Figure 2 Point biserial correlation coefficients between each item of the French version of the PRCS and the overall scale score (from item I to item 6).

Abbreviations: PRCS, Personal Report of Confidence as a Speaker; $r_{p b}$, point biserial correlation.

significant, it should be noted that the item-total correlation was smaller for item $6\left(\mathrm{r}_{\mathrm{pb}}=0.388\right)$. However, the descriptive statistics as well as the contribution of this item to the scale score reliability suggested that it should not be removed from the scale. Future studies should address this issue.

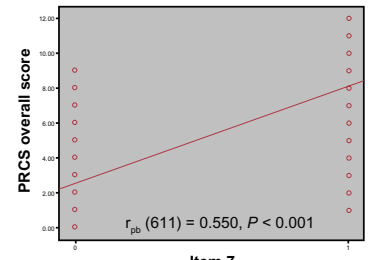

Item 7

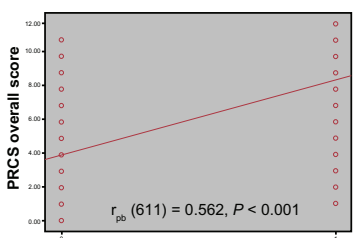

Item 9

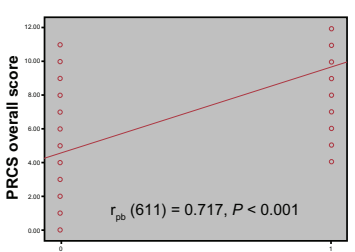

Item 1
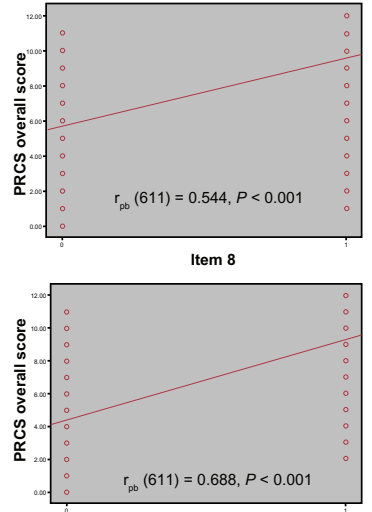

Item 10

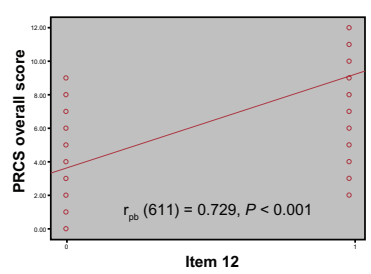

Figure 3 Point biserial correlation coefficients between each item of the French version of the PRCS and the overall scale score (from item 7 to item 12). Abbreviations: PRCS, Personal Report of Confidence as a Speaker; $r_{p b}$, point biserial correlation.
Table 5 Correlations between the PRCS and other measurements of psychopathology

\begin{tabular}{lllll}
\hline & FNE & LSAS & STAI-Trait & BDI-II \\
\hline PRCS & $0.414^{* *}$ & $0.522^{* *}$ & $0.516^{* *}$ & $0.36 I^{* *}$ \\
FNE & - & $0.39 I^{* *}$ & $0.542^{* *}$ & $0.338^{* *}$ \\
LSAS & & - & $0.469 * *$ & $0.402^{* *}$ \\
STAI-Trait & & & - & $0.739 * *$ \\
\hline
\end{tabular}

Note: $* * P<0.01$.

Abbreviations: PRCS, Personal Report of Confidence as a Speaker; FNE, Fear of Negative Evaluation scale; LSAS, Liebowitz Social Anxiety Scale; STAI-Trait, Trait-version of the Spielberger State-Trait Anxiety Inventory; BDI-II, Beck Depression Inventory (2nd edition).

In conclusion, the French version of the 12 -item version of the PRCS provides a valid measure of fear of public speaking. Regarding its structural validity, confirmatory factor analyses replicated the model implied by the exploratory analyses of Hook et al. ${ }^{33}$ These results suggest there is good reason to interpret the scale score according to a singlefactor solution (ie, a global score). Good scale reliability and concurrent validity were also observed. These findings have critical consequences for the evaluation of individuals who fears public speaking.

\section{Acknowledgments}

This work was supported in part by a Joined Research Grant from the Belgian French Community (awarded to Pierre Philippot) and by a postdoctoral research fellow grant from the Belgian National Fund for Scientific Research (awarded to Alexandre Heeren).

\section{Disclosure}

The authors report no conflicts of interest in this work.

\section{References}

1. Furmark T, Tillfors M, Everz P, Marteinsdottir I, Gefvert O, Fredrikson M. Social phobia in the general population: prevalence and sociodemographic profile. Soc Psychiatry Psychiatr Epidemiol. 1999; 34(8):416-424.

2. Ruscio AM, Brown TA, Chiu WT, Sareen J, Stein MB, Kessler RC. Social fears and social phobia in the USA: results from the National Comorbidity Survey Replication. Psychol Med. 2008;38(1):15-28.

3. Aderka IM, Hofmann SG, Nickerson A, Hermesh H, Gilboa-Schechtman E, Marom S. Functional impairment in social anxiety disorder. $J$ Anxiety Disord. 2012;26(3):393-400.

4. Greenberg PE, Sisitsky T, Kessler RC, et al. The economic burden of anxiety disorders in the 1990s. J Clin Psychiatry. 1999;60(7):427-435.

5. American Psychiatric Association. Diagnostic and Statistical Manual of Mental Disorders-DSM IV-TR. Washington, DC: American Psychiatric Association; 1994.

6. Furmark T, Tillfors M, Stattin H, Ekselius L, Fredrikson M. Social phobia subtypes in the general population revealed by cluster analysis. Psychol Med. 2000;30(6):1335-1344.

7. Tillfors M, Furmark T. Social phobia in Swedish university students: prevalence, subgroups, and avoidant behavior. Soc Psychiatry Psychiatr Epidemiol. 2007;42(1):79-86. 
8. Blöte AW, Klint MJ, Miers AC, Westenberg PM. The relation between public speaking anxiety and social anxiety: a review. J Anxiety Disord. 2009;23(3):305-313.

9. Bögels SM, Alden L, Beidel DC, et al. Questions and answers for the DSM-V. Depress Anxiety. 2010;27(2):168-189.

10. England EL, Herbert JD, Forman EM, Rabin SJ, Juarascio A, Goldstein SP. Acceptance-based exposure therapy for public speaking anxiety. Journal of Contextual and Behavioral Science. 2012;1(1-2): 66-72.

11. Wallach HS, Safir MP, Bar-Zvi M. Virtual reality cognitive therapy for public speaking anxiety: a randomized clinical trial. Behav Modif. 2009;33(3):314-338.

12. Anderson PL, Zimand E, Hodges LF, Rothbaum BO. Cognitive behavioral therapy for public-speaking anxiety using virtual reality for exposure. Depress Anxiety. 2005;22(3):156-158.

13. Robillard G, Bouchard S, Dumoulin S, Guitard T, Klinger E. Using virtual humans to alleviate social anxiety: preliminary report from a comparative outcome study. Stud Health Technol Inform. 2010;154:57-60.

14. Heeren A, Lievens L, Philippot P. How does attention training work in social phobia: disengagement from threat or re-engagement to nonthreat? J Anxiety Disord. 2011;25(8):1108-1115.

15. Amir N, Weber G, Beard C, Bomyea J, Taylor CT. The effect of a single-session attention modification program on response to a publicspeaking challenge in socially anxious individuals. J Abnorm Psychol. 2008;117(4):860-868.

16. Beard C, Weisberg RB, Amir N. Combined cognitive bias modification treatment for social anxiety disorder: a pilot trial. Depress Anxiety. 2011; 28(11):981-988.

17. Guastella AJ, Richardson R, Lovibond PF, et al. A randomized controlled trial of D-cycloserine enhancement of exposure therapy for social anxiety disorder. Biol Psychiatry. 2008;63(6):544-549.

18. Bergamaschi MM, Queiroz RH, Chagas MH, et al. Cannabidiol reduces the anxiety induced by simulated public speaking in treatmentnaïve social phobia patients. Neuropsychopharmacology. 2011;36(6): 1219-1226.

19. McCroskey JC. An Introduction to Rhetorical Communication, 2nd ed. Boston, MA: Allyn and Bacon; 1997.

20. Hofmann SG, DiBartolo PM. An instrument to assess self-statement during public speaking: scale development and preliminary psychometrics properties. Behav Ther. 2000;31(3):499-515.

21. Gilkinson H. Social fears as reported by students in college speech classes. Speech Monographs. 1942;9(1):141-160.

22. Paul GL. Insight vs Desensitization in Psychotherapy. Stanford, CA. Stanford University Press; 1966.

23. Fredrikson M, Klein K, Ohman A. Do instructions modify effects of beta-adrenoceptor blockade on anxiety? Psychophysiology. 1990;27(3): 309-317.

24. Jones G, Phillips G, Rieger E. Effects of cardiac awareness, public speaking anxiety, and physiological priming on state-trait anxiety (state) and feelings of apprehension. Psychophysiology. 1995;32:S43.

25. Altmaier EM, Ross SL, Leary MR, Thornborough M. Matching stress inocuation's treatment components to clients' anxiety mode. J Couns Psychol. 1982;29(3):331-334.

26. Cunningham V, Lefkoe M, Sechrest L. Eliminating fears: an intervention that permanently eliminates the fear of public speaking. Clinical Psychology and Psychotherapy. 2006;13(3):183-193.

27. Deffenbacher J, Michaels A, Daley P, Michaels T. A comparison of homogeneous and heterogeneous anxiety management training. J Couns Psychol. 1980;27(6):630-634.

28. Kirsh I, Henry D. Extinction versus credibility in the desensitization of speech anxiety. J Consult Clin Psych. 1977;45(6):1052-1059.

29. Lent RW, Russel RK, Zamostny KP. Comparison of cue-controlled desensitization, rational restructuring, and a credible placebo in the treatment of speech anxiety. J Consult Clin Psychol. 1981;49(4):608-610.

30. Phillips GC, Jones GE, Rieger EJ, Snell JB. Normative data for the personal report of confidence as a speaker. J Anxiety Disord. 1997;11(2): 215-220.
31. Daly JA. The assessment of social-communicative anxiety via selfreports: a comparison of measures. Commun Monogr. 1978;45(3): 204-218.

32. Tarico VS, van Velzen DR, Altmaier EM. Comparison of thought-listing rating methods. J Couns Psychol. 1986;33(1):81-83.

33. Hook JN, Smith CA, Valentiner DP. A short-form of the Personal Report of Confidence as a Speaker. Pers Individ Dif. 2008;44(6): $1306-1313$

34. Gallego MJ, Botella C, Quero S, Garcia-Palacios A, Baños RM. Validation of the Personal Report Confidence as speaker in a Spanish clinical sample. Behav Psychol. 2009;17(3):413-431.

35. Méndez FX, Inglés CJ, Hidalgo MD. The shortened Spanish version of the Personal Report of Confidence as Speaker: reliability and validity in adolescent population. Behavioral Psychology. 2004;12(1): $25-42$.

36. Hambleton RK, Merenda PF, Spielberger CD, editors. Adapting Educational and Psychological Tests for Cross-Cultural Assessment. Hillsdale, NJ: Lawrence Erlbaum Associates, Inc; 2005.

37. Liebowitz MR. Social phobia. Mod Probl Pharmacopsychiatry. 1987;22:141-173.

38. Watson D, Friend R. Measurement of social-evaluative anxiety. J Consult Clin Psychol. 1969;33(4):448-457.

39. Spielberger CD, Gorsuch RL, Lushene R, Vagg PR, Jacobs G. Manual for the State-Trait Anxiety Inventory. Palo Alto, CA: Consulting Psychologists Press; 1983.

40. Beck AT, Steer RA, Brown GK. Beck Depression Inventory Manual, 2nd ed. San Antonio, TX: Psychological Corporation (French adaptation); Paris, France: Editions du Centre de Psychologie Appliquée; 1998.

41. Heeren A, Douilliez C, Peschard V, Debrauwere L, Philippot P. Cross-cultural consistency of the Five Facets Mindfulness Questionnaire: adaptation and validation in a French-speaking sample. Eur Rev Appl Psychol. 2011;61(3):147-151.

42. Monestes JL, Villatte M, Mouras H, Loas G, Bond FW. French translation and validation of the acceptance and action questionnaire (AAQ-II). Eur Rev Appl Psychol. 2009;59(4):301-308.

43. Bruchon-Schweitzer M, Paulhan I. Adaptation Francophone de L'inventaire D'anxiété Trait-Etat (Forme Y) de Spielberger [French adaptation of the Spielberger's State-Trait Anxiety Inventory]. Paris, France: Editions du Centre Psychologie Appliquée; 1993

44. Heeren A, Maurage P, Rossignol M, et al. Self-report version of the Liebowitz Social Anxiety Scale: psychometric properties of the French version. Can J Behav Sci. 2012;44(2):99-107.

45. Musa CN, Kostogianni N, Lépine JP. The Fear of Negative Evaluation Scale (FNE): psychometric properties of the French version. Encephale. 2004;30(6):517-524. French.

46. Arbuckle JL. Amos ${ }^{\mathrm{TM}} 16.0$ User's Guide. Spring House, PA: Amos Development Corporation; 2007.

47. Byrne BM. Structural Equation Modeling with EQS and EQS/Windows. Thousand Oaks, CA: Sage; 1994.

48. Wheaton B, Muthén B, Alwin DF, Summers GF. Assessing reliability and stability in panel models. In: Heise DR, editor. Sociological Methodology. San Francisco, CA: Jossey-Bass, Inc; 1977:84-136.

49. Bollen KA. Structural Equations with Latent Variables. New York, NY: Wiley-Interscience; 1989.

50. Schweizer K. Some guidelines concerning the modeling of traits and abilities in test construction. Eur J Psychol Assess. 2010;26(1):1-2.

51. $\mathrm{Hu} \mathrm{LT}$, Bentler PM. Fit indices in covariance structure modeling: sensitivity to underparameterized model misspecification. Psychol Methods. 1998;3(4):424-453.

52. Hu LT, Bentler PM. Cutoff criteria for fit indices in covariance structure analysis: conventional criteria versus new alternatives. Struct Equ Modeling. 1999;6(1):1-55.

53. Ullman JB. Structural equation modelling. In: Tabachnick BG, Fidell LS, editors. Using Multivariate Statistics, 4th ed. Boston: Allyn \& Bacon; 2001:653-771.

54. Bentler PM. Comparative fit indexes in structural models. Psychol Bull. 1990;107(2):238-246. 
55. Hoyle RH, Panter AT. Writing about structural equation models. In: Hoyle RH, editor. Structural Equation Modeling, Concepts, Issues, and Applications. Thousand Oaks, CA: Sage Publications, Inc; 1995:158-176.

56. Marsh HW, Balla JR, McDonald RP. Goodness-of-fit indices in confirmatory factor analysis: the effects of sample size. Psychol Bull. 1988;102:391-410.

57. Cole DA. Utility of confirmatory factor analysis in test validation research. J Consult Clin Psychol. 1987;55(4):584-594.

58. Beauducel A, Wittmann WW. Simulation study on fit indexes in CFA based on data with slightly distorted simple structure. Structural Equation Modeling. 2005;12(1):41-75.

59. Nunnally J. Psychometric Theory, 2nd ed. New York, NY: McGraw-Hill; 1978.
60. Meng XL, Rosenthal R, Rubin DB. Comparing correlated correlation coefficients. Psychol Bull. 1992;111(1):172-175.

61. Heeren A, Reese HE, McNally R, Philippot P. Attention training toward and away from threat in social phobia: effects on subjective, behavioral, and physiological measures of anxiety. Behav Res Ther. 2012;50(1):30-39.

62. Rossignol M, Campanella S, Maurage P, Heeren A, Falbo L, Philippot P. Enhanced perceptual responses during visual processing of facial stimuli in young socially anxious individuals. Neurosci Lett. 2012;526(1):68-73.

63. Buchanan T, Ali T, Heffernan TM, et al. Nonequivalence of online and paper-and-pencil psychological tests: the case of the prospective memory questionnaire. Behav Res Methods. 2005;37(1): $148-154$. 


\section{Supplementary materials}

Table SI French version of the PRCS

\begin{tabular}{lcc}
\hline I. Mes mains tremblent quand j'essaie de manipuler des objets sur l'estrade/face à l'audience. & $\mathrm{V}$ & $\mathrm{F}$ \\
2. Je suis dans la crainte constante d'oublier mon discours. & $\mathrm{V}$ & $\mathrm{F}$ \\
3. Lorsque je prépare un discours, je suis dans un état d'anxiété constant. & $\mathrm{V}$ \\
4. Mes pensées deviennent confuses et se mélangent quand je parle devant une audience. & $\mathrm{V}$ \\
5. Même si je parle facilement avec des amis, je cherche mes mots sur l'estrade/face à l'audience. & $\mathrm{V}$ \\
6. Les visages de mon audience sont flous quand je les regarde. & $\mathrm{V}$ \\
7. Je me sens dégouté(e) de moi-même après avoir essayé de m'adresser à un groupe de personnes. & $\mathrm{V}$ \\
8. Je transpire et tremble juste avant de me lever pour parler. & $\mathrm{V}$ \\
9. Ma posture parait tendue et anormale. & $\mathrm{V}$ \\
10. J'ai peur et je suis tendu(e) pendant tout le temps où je parle devant un groupe de personnes. & $\mathrm{F}$ \\
II. C'est difficile pour moi de chercher calmement dans ma tête les bons mots pour exprimer mes pensées. & $\mathrm{F}$ \\
12. Je suis terrifié(e) à l'idée de parler devant un groupe de personnes. & $\mathrm{F}$ \\
\hline
\end{tabular}

Notes: Ce questionnaire est composé de 12 questions examinant vos émotions lors de situations de prise parole en public (par exemple, présentation professionnelle, discours à un mariage). Pour chaque question, en vous remémorant ce que vous avez ressenti lors de votre dernière présentation en public, veuillez déterminer si la phrase a plutôt tendance à vous correspondre (vrai; V) ou non (faux, F). Répondez aux questions rapidement, sans trop y réfléchir. C'est votre première impression qui nous intéresse.

Abbreviation: PRCS, Personal Report of Confidence as a Speaker scale.

Table S2 Standardized factor loadings of model B

\begin{tabular}{ll}
\hline PRCS items & Loadings \\
\hline I. My hands tremble when I try to handle objects on the platform. & $0.269^{* *}$ \\
2. I am in constant fear of forgetting my speech. & $0.462^{* *}$ \\
3. While preparing a speech I am in a constant state of anxiety. & $0.42 I^{* *}$ \\
4. My thoughts become confused and jumbled when I speak before the audience. & $0.437^{* *}$ \\
5. Although I talk fluently with friends I am at a loss for words on the platform. & $0.410^{* *}$ \\
6. The faces of my audience are blurred when I look at them. & $0.086^{* *}$ \\
7. I feel disgusted with myself after trying to address a group of people. & $0.275^{* *}$ \\
8. I perspire and tremble just before getting up to speak. & $0.200^{* *}$ \\
9. My posture feels strained and unnatural. & $0.254^{* *}$ \\
I0. I am fearful and tense all the while I am speaking before a group of people. & 0.45 I** \\
II. It is difficult for me to search my mind calmly for the right words to express my thoughts. & $0.4 I 8^{* *}$ \\
I2. I am terrified at the thought of speaking before a group of people. & $0.504^{* *}$ \\
\hline
\end{tabular}

Note: $* * P<0.01$.

Abbreviation: PRCS, Personal Report of Confidence as a Speaker scale.

\section{Publish your work in this journal}

Neuropsychiatric Disease and Treatment is an international, peerreviewed journal of clinical therapeutics and pharmacology focusing on concise rapid reporting of clinical or pre-clinical studies on a range of neuropsychiatric and neurological disorders. This journal is indexed on PubMed Central, the 'PsycINFO' database and CAS.
The manuscript management system is completely online and includes a very quick and fair peer-review system, which is all easy to use. Visit http://www.dovepress.com/testimonials.php to read real quotes from published authors. 